\title{
Omalizumab for severe asthma: toward personalized treatment based on biomarker profile and clinical history
}

This article was published in the following Dove Press journal:

Journal of Asthma and Allergy

\author{
Farnaz Tabatabaian \\ Dennis K Ledford \\ Division of Allergy and Immunology, \\ Department of Internal Medicine, \\ Morsani College of Medicine, \\ University of South Florida, Tampa, \\ FL, USA
}

\begin{abstract}
Asthma is a heterogeneous syndrome with numerous underlining molecular and inflammatory mechanisms contributing to the wide spectrum of clinical phenotypes. Multiple therapies targeting severe asthma with type 2 (T2) high inflammation are or soon will be available. T2 high inflammation is defined as inflammation associated with atopy or eosinophilia or an increase in cytokines associated with T-helper 2 lymphocytes. Omalizumab is a humanized anti-IgE monoclonal antibody and the first biologic therapy approved for moderate-severe allergic asthma. Despite the specificity of biologic therapies like omalizumab, clinical response is variable, with approximately $50 \%$ of treated patients achieving the primary outcome. A prior identification of the ideal candidate for therapy would improve patient outcomes and optimize the use of health care resources. As the number of biologic therapies for asthma increases, the goal is identification of biomarkers or clinical phenotypes likely to respond to a specific therapy. This review focuses on potential biomarkers and clinical history that may identify responders to omalizumab therapy for asthma.
\end{abstract}

Keywords: severe persistent asthma, asthma phenotype and endotype, T2 high inflammation, omalizumab, asthma biomarkers, eosinophils, fractional exhaled nitric oxide, $\operatorname{IgE}$

\section{Introduction}

Asthma is a complicated chronic disease that affects $7 \%-13 \%$ of the population, resulting in increasing morbidity and annual utilization of US $\$ 19.7$ billion in health care. ${ }^{1}$ The current literature states that $10 \%$ of patients with asthma are poorly controlled, contributing to high utilization of health care resources and negative impact on quality of life. ${ }^{2}$ Severe asthma or exacerbation-prone asthma is defined in various ways. The European Respiratory Society and American Thoracic Society have defined severe asthma as a "condition that requires treatment with high doses of inhaled corticosteroids [ICSs] plus a second controller and/or systemic corticosteroids to prevent it from becoming 'uncontrolled' or from remaining 'uncontrolled' despite this therapy". ${ }^{1,3}$ In other studies, severe asthma is defined as subjects with refractory symptoms and exacerbation while on three controller medications. Despite current definitions, guidelines, and management algorithms, some subjects with persistent asthma are uncontrolled. Choosing the correct therapy to achieve control in severe persistent asthma remains a challenge in the clinical setting. The phenotype, clinical presentation, and the endotype, molecular mechanism of inflammation in the lungs, play an important role in selecting appropriate targeted therapy.
Correspondence: Dennis K Ledford Division of Allergy and Immunology, Department of Internal Medicine, Morsani College of Medicine, James A Haley VA Hospital, University of South Florida, 12901 Bruce B Downs Boulevard - MCD 19, Tampa, FL 33612, USA

Email dledford@health.usf.edu 
Various phenotypic manifestations of refractory asthma based on triggers, radiographic findings, severity, response to treatment, viral infections, obesity, or cigarette smoking are discussed in the literature. Cluster analysis of severe or uncontrolled asthma, as developed in SARP and other studies, illustrate that early (childhood)-onset asthma is associated with atopic disease and allergic conditions, whereas late- or adultonset asthma is more commonly associated with obesity and female sex. In general, severity of airflow obstruction correlates with frequency of exacerbations. ${ }^{4,5}$ Despite their providing some insight into the complexity of persistent asthma, the clinical value of such cluster analyses in improving asthma outcomes is not apparent. ${ }^{6}$ The link between clinical phenotype and molecular mechanism could be the key in adding appropriate add-on therapy and optimization of control in severe asthma.

Allergic asthma is an observable clinical phenotype. $\operatorname{IgE}$ is integral to the pathophysiology of allergic asthma. Omalizumab (Xolair; Genentech, San Francisco, CA, and Novartis, Basel, Switzerland) is a humanized monoclonal antibody with specificity for the IgE molecule at the binding site for the high-affinity IgE receptor. Omalizumab is approved as an add-on therapy for moderate-severe allergic asthma in children (6-18 years old, with pediatric dosing for $6-<12$ years of age and subsequent dose adjustment for adolescents aged 12 years and older) and adults in the US, Europe, and many other territories. ${ }^{7}$ The reality of the situation is that treatment with omalizumab is expensive and cost-effective only in a subset of treated patients. It is imperative but challenging for clinicians to identify individuals most likely to have therapeutic benefit. This review focuses on individualized therapy and patient selection for omalizumab. The intent is to highlight current measurable molecular mechanisms, clinical characteristics, and available biomarkers that may assist in identifying ideal candidates for therapy.

\section{Types of inflammation in asthma}

The current hypothesis suggests two major inflammatory categories of asthma: type 2 (T2) high and T2 low. T2 low includes a heterogeneous group of asthma phenotypes including paucigranular, $\mathrm{T}_{\mathrm{H}} 9$ high, and $\mathrm{T}_{\mathrm{H}} 17$ high (neutrophilic). Neutrophilic infiltration in T2 low is attributed to increased expression of $\mathrm{T}_{\mathrm{H}} 17$ cytokines, including IL17, IL21, and IL22, ${ }^{8}$ whereas in T2 high a predominance of eosinophils in the sputum and airways occurs with increased expression of type 2 cytokines, including IL4, IL5, and IL13. ${ }^{9}$ For the purpose of this review, we focus on molecular mechanisms of T2 high inflammation and associated biomarkers, since this is the more likely group for which omalizumab will be effective.
Allergic asthma results from a response to an exogenous peptide or antigen in a sensitized individual. Genetic and environmental factors impact sensitization. Through exposure to an allergen, an inflammatory cascade occurs, suggestive of T2 high inflammation (Figure 1). Allergen exposure contributes to the production of IL33, IL25, and TSLP by epithelial cells. These alarmins stimulate ILC2, $\mathrm{T}_{\mathrm{H}} 2$, and mast cells. Simultaneously, the antigen is processed by dendritic cells and presented to naïve $T$ cells, contributing to further differentiation to $\mathrm{T}_{\mathrm{H}} 2$ cells. This complex cross talk among cells allows for an environment rich in IL4, IL5, and IL13. ${ }^{9}, 10$ IL4 and IL13 promote the production of IgE by B cells, ${ }^{9}$ IL 5 affects eosinophil biology, and IL13 may be important in airway remodeling.

It is important to acknowledge $\operatorname{IgE}$ as one of the key factors in $\mathrm{T} 2$ high inflammation, and the presence of specific $\operatorname{IgE}$ identifies an individual as atopic. Two primary IgE receptors are known: 1) the high-affinity receptor, FceRI, predominantly found on mast cells and basophils in tetrameric form and in trimeric form on antigen-presenting cells; and 2) the low-affinity receptor, FceRII (CD23), found on B cells and other hematopoietic cells. ${ }^{11-13}$ The density of both receptors is correlated directly with the concentration of blood $\operatorname{IgE}$. Allergen sensitization results in specific IgE binding to FceRI on mast cells and basophils. Subsequent exposure to allergens cross-links the membrane-bound IgE on mast cells and basophils, resulting in the release of intracellular mediators, as well as contributing to T2 high inflammation. ${ }^{1,13,14}$

\section{Role of omalizumab in T2 high inflammation}

Omalizumab blocks the interaction of IgE with FceRI on mast cells, antigen-presenting cells, and basophils by selectively binding to free IgE..$^{15,16}$ Omalizumab indirectly downregulates FceRI expression on basophils, mast cells, and dendritic cells, affecting type 2 cytokine production and inhibiting T2 inflammation (Figure 2). ${ }^{14}$ In 2013, Chan et al found that omalizumab also targeted IgE-bearing B cells, causing a state of anergy and unresponsiveness to antigenic/allergen stimulation. ${ }^{17}$

Multiple studies have demonstrated the efficacy of omalizumab in reducing asthma exacerbations by $30 \%-60 \%$ with minimal change in lung function and modest symptom improvement. Omalizumab treatment reduces the need for rescue systemic CS therapy, but does not reduce maintenance systemic CS therapy. ${ }^{18,19}$ It is the first asthma therapy to target a specific subtype of asthma: moderate-severe asthma with blood IgE in a specific range and evidence of sensitization to perennial allergens. Despite the knowledge of the mechanism 


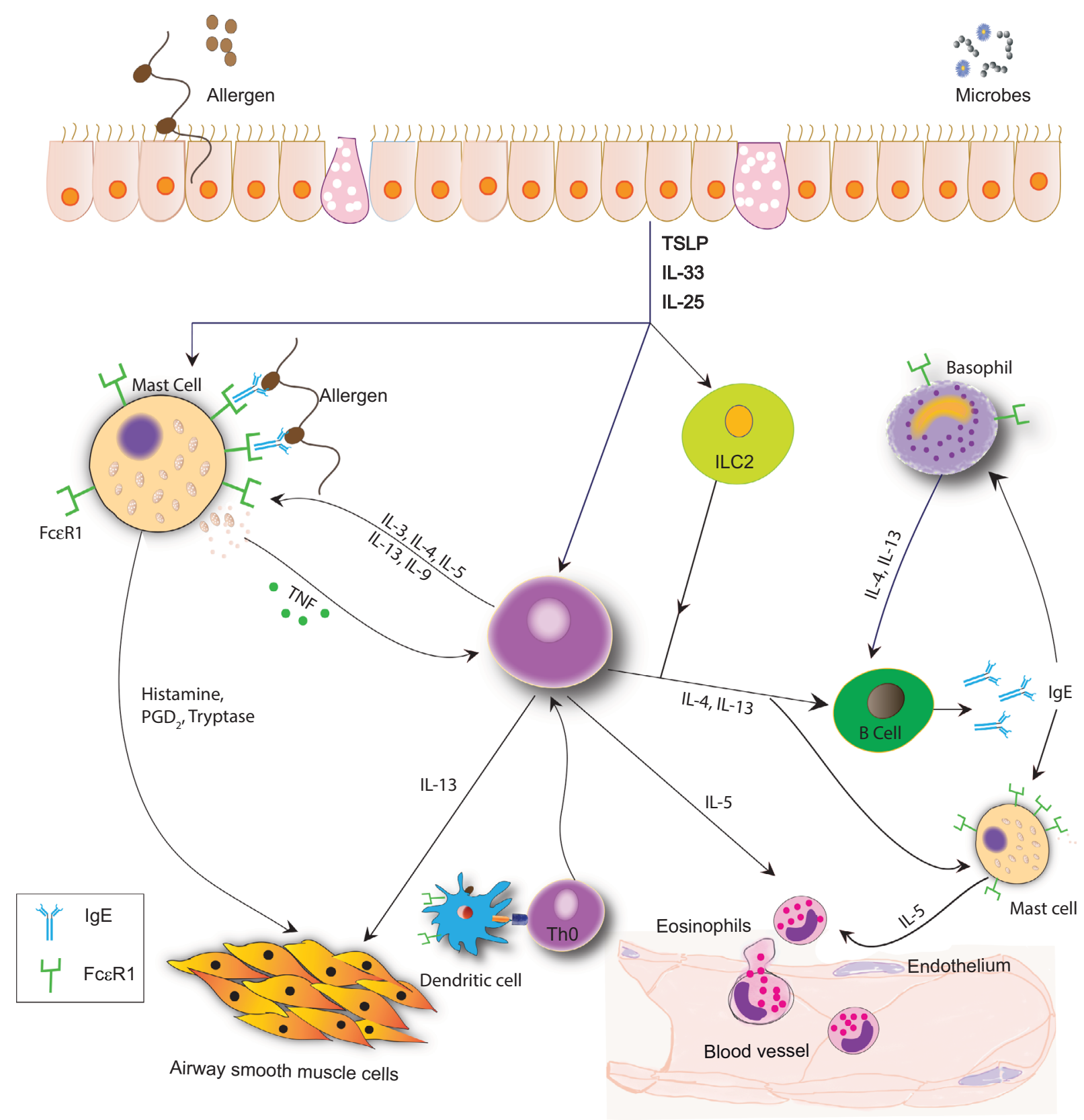

Figure I Complex cross talk in T2 high inflammation.

Notes: Epithelial cells secrete TSLP, IL33, and IL25, which stimulate mast cells, and $\mathrm{T}_{\mathrm{H}} 2$ and ILC2. $\mathrm{T}_{\mathrm{H}} 2$ and ILC2 cells share many features, and both are involved in the secretion of type 2 cytokines, including IL4, ILI3, and IL5. B cells undergo class switch under the influence of IL4, increasing production of IgE. ILI 3 affects smooth muscles and airway remodeling. IL5 contributes to the production and migration of eosinophils to the site of inflammation. Data from Galli and Tsai ${ }^{13}$ and Lambrecht and Hammad. ${ }^{49}$

of action and selection of treated subjects based upon total and specific IgE, clinical studies and 13 years of use demonstrate that the response is variable and not readily predicted. In a retrospective analysis of the EXTRA trial, Hanania et al identified possible biomarkers predictive of omalizumab response, including fractional exhaled nitric oxide (FeNO), peripheral blood eosinophils, and serum periostin. ${ }^{20}$ This was the first study of omalizumab therapy that separated patients into categories of T2 high vs T2 low inflammation. Significant reduction in asthma exacerbations was noted in the T2 high and but not in the T2 low subgroups, providing some guidance in identifying individuals for omalizumab treatment.

\section{Biomarkers that predict responsiveness to omalizumab}

Understanding T2 high molecular inflammation has opened the doors to pursuing more targeted therapy in severe allergic asthma. Clinical biomarkers have long been used in medicine to evaluate the risk of a disease state, responsiveness to medications, and even progression of disease. Biomarkers may be 


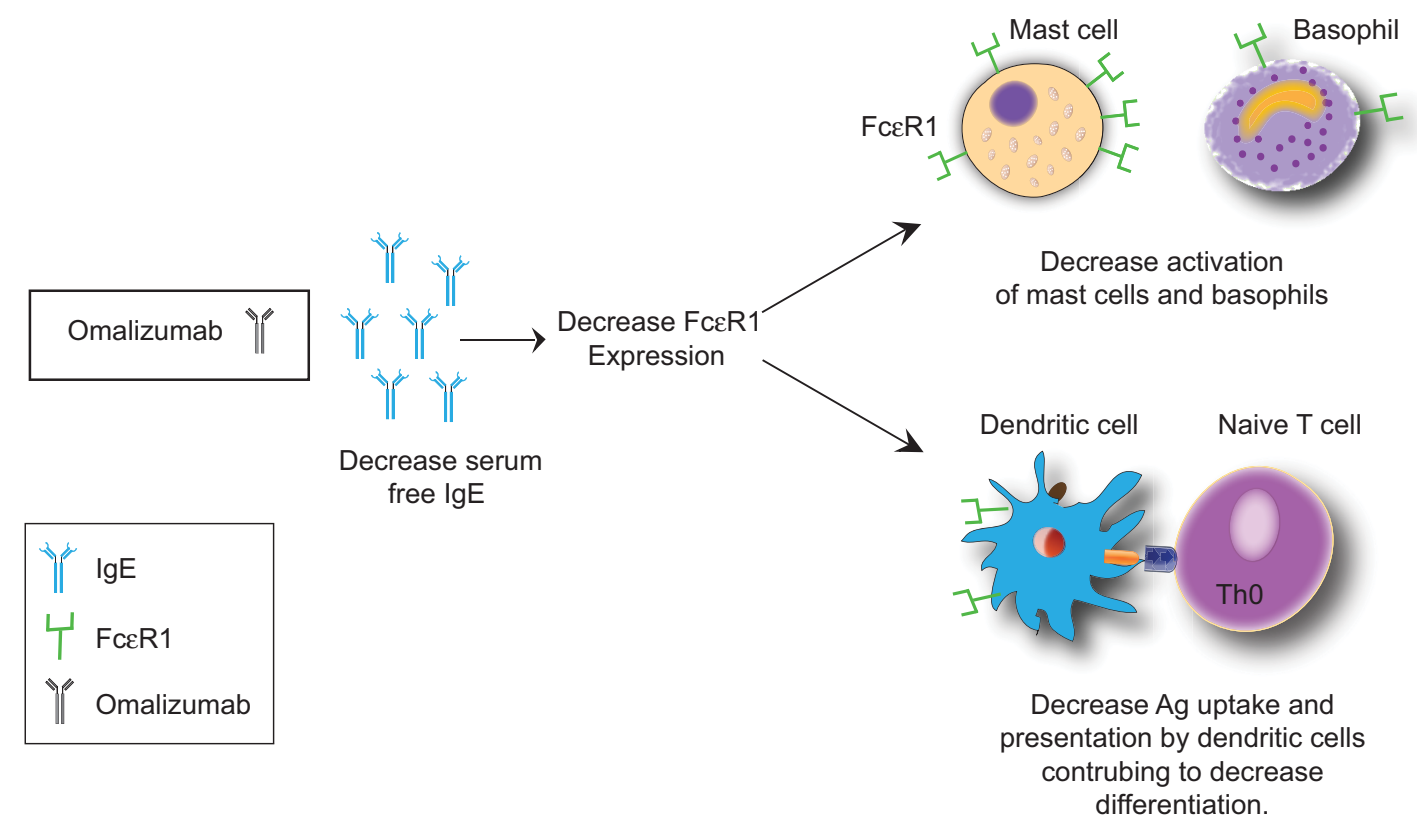

Figure 2 Omalizumab causes a decrease in serum free lgE.

Notes: The lgE decrease subsequently impacts expression of FceRI on surfaces of mast cells, basophils, dendritic cells, and eosinophils. This causes decreased activation of mast cells and basophils. Cross talk between dendritic and naïve T cells is decreased, impacting the shift toward $\mathrm{T}_{\mathrm{H}} 2$ cells. Data from Kupryś-Lipińska et al. ${ }^{50}$

divided into three types: type 0 assess the natural history of the disease state, type 1 predict responsiveness to treatment, and type 2 identify risk for particular diseases. ${ }^{21}$ Type 0 biomarkers are not identified for asthma. In T2 high asthma, several biomarkers have been identified and studied with respect to responsiveness of drug therapy. These include increased FeNO; blood eosinophils, periostin, total IgE, and antigen-specific $\mathrm{IgE}$; and low forced expiratory volume in 1 second $\left(\mathrm{FEV}_{1}\right)^{20}$

\section{Eosinophils}

Elevated blood eosinophils have been associated with more severe asthma and predict a higher risk of asthma exacerbation. ${ }^{21-23}$ In fact, in a large UK cohort, patients with blood eosinophil counts $\geq 400$ cells $/ \mathrm{mL}$ experienced more severe asthma exacerbations and had poorer asthma control than those with $<400$ cells $/ \mathrm{mL} .{ }^{24}$ Obtaining peripheral eosinophil counts is relatively easy, and while not an optimal surrogate for airway eosinophils, it is suggestive of possible underlying T2 high inflammation. Treatment with omalizumab may decrease peripheral blood eosinophil counts. ${ }^{25}$ In a recent pooled analysis of the two pivotal Phase III double-blind, placebocontrolled registration trials of omalizumab in allergic asthma, eosinophil counts $>300$ cells $/ \mathrm{mL}$ were associated with higher disease activity and better response to omalizumab. ${ }^{26}$ Similar findings were demonstrated by Busse et al in a prospective 24-week multicenter parallel-group, double-blind randomized placebo-control trial, which showed that omalizumab-treated individuals with an eosinophil count $\geq 300 / \mathrm{mL}$ or more had a $59 \%$ reduction in protocol-defined exacerbations compared to placebo. ${ }^{27}$ In a randomized double-blind multicenter study evaluating persistent response to omalizumab, Ledford et al reported subjects treated with omalizumab therapy with higher peripheral blood eosinophil counts were more likely to suffer asthma exacerbations if omalizumab was discontinued. ${ }^{16}$ Therefore, omalizumab seems to have greater efficacy in patients with increased baseline peripheral eosinophil counts, and blood eosinophil quantification is a practical biomarker in predicting relapse if omalizumab is discontinued.

Other markers of eosinophils may be useful measures of respiratory disease. For example, eosinophil peroxidase, an eosinophil-granule component, is strongly correlated with induced sputum eosinophils. ${ }^{28}$ Bioactive strips that measure eosinophil peroxidase as a point-of-care tool in a clinical setting is in development. ${ }^{29}$

\section{Fractional exhaled nitric oxide}

Measurement of FeNO is a noninvasive way to potentially quantify T2 high airway inflammation. Similar to sputum and blood eosinophils, elevated FeNO is predictive of asthma exacerbations and asthma severity. In the lung, oxidation of the amino acid L-arginine through NO synthase (NOS) produces NO. Three isoforms of NOS have been described: neural, endothelial, and inducible. A variety of cells - epithelial, inflammatory (macrophages, mast cells, and neutro- 
phils), neuronal airway, and vascular endothelial - express the various isoforms of NOS. Inducible NOS is expressed in high quantity in epithelial cells lining the airway wall and alveoli. This increase in expression of inducible NOS contributes to increase in production of NO under the influence of IL4 and IL13. ${ }^{20}$ Several analyzers are available commercially for the measurement of NO concentration in the lungs. These include NiOx Mino, NiOx Vero (Circassia, Oxford, UK), and NO Breath (Bedfont Scientific, Maidstone, UK).

The American Thoracic Society has proposed FeNO guidelines for clinical use, with FeNO $<25 \mathrm{ppb}$ in adults and $<20 \mathrm{ppb}$ in children proposed as normal. ${ }^{30}$ Adults with FeNO $>50 \mathrm{ppb}$ are more responsive to ICSs, with a decrease in FeNO within 1 week of therapy. ${ }^{31}$ If FeNO remains $>50$ $\mathrm{ppb}$ in adults ( $>35 \mathrm{ppb}$ in children) despite ICS use, then one should consider noncompliance or decreased CS responsiveness. ${ }^{21,30}$ In a Cochrane review of all randomized controlled trials in both children and adults comparing adjustment of asthma medications based on FeNO levels to those not using FeNO, a decrease in FeNO was associated with a reduction in the number of asthma exacerbations, but not associated with improvement in day-to-day symptoms or reduction in total ICS used..$^{32,33}$ Mansur et al and Hanania et al independently demonstrated that patients with severe asthma and higher baseline FeNO had a greater reduction in exacerbations with omalizumab compared to placebos..$^{20,25}$ An FeNO of greater than $49 \mathrm{ppb}$ in children within 4 weeks of ICS discontinuation was associated with an increase in asthma exacerbations. ${ }^{34}$ Similarly, an increase in FeNO after discontinuation of longterm omalizumab predicted exacerbation. ${ }^{16}$ It is interesting that anti-IL5 biologics decrease serum and sputum eosinophils, but do not have much effect on FeNO. ${ }^{35}$

Clinically, it is important to note that FeNO can be impacted by many host and environmental factors. In particular, exercise and spirometry prior to measuring FeNO can cause a transient decrease in readings. ICSs, systemic CSs, leukotriene-receptor antagonists, and smoking have been associated with reduction in FeNO. FeNO is higher in males than females. In children, FeNO increases at a rate of 5\% per year, likely attributable to increased height. High-nitrate foods have also been associated with an increase in FeNO. However, the relative ease of measurement of FeNO at the bedside allow it to serve as a biomarker for T2 high inflammation predicting response to omalizumab.

\section{Periostin}

Blood periostin is another biomarker of T2 high inflammation. It is secreted by airway epithelial cells and fibroblasts in response to IL13. ${ }^{21}$ Gene expression is increased in asthma.
Subjects with higher baseline periostin have a greater improvement in $\mathrm{FEV}_{1}$ than those with low periostin while being treated with an IL13 antagonist. ${ }^{36}$ In the EXTRA study, the high-periostin group ( $>50 \mathrm{ng} / \mathrm{mL}$ at baseline) had $30 \%$ reduction in asthma exacerbations after treatment with omalizumab compared to $3 \%$ reduction in the low-periostin group $(<50 \mathrm{ng} /$ $\mathrm{mL}$ at baseline). ${ }^{20} \mathrm{~A}$ prospective observational study assessed the utility of serum periostin and total IgE to predict response to omalizumab, as determined by the absence of asthma exacerbations during the first year of treatment. The high-periostin group ( $>60 \mathrm{ng} / \mathrm{mL}$ ) experienced less frequent asthma exacerbations and achieved a clinically significant change in Asthma Quality of life Questionnaire (AQLQ) scores at 16 weeks compared to the low-periostin group $(<60 \mathrm{ng} / \mathrm{mL}) .{ }^{37}$ Unfortunately, while serum periostin may be predictive of response to omalizumab, the assay is not commercially available.

\section{Total serum IgE and antigen-specific lgE}

Total serum $\operatorname{IgE}$ and specific IgE are the most readily recognized risk factors for allergic asthma. In a cluster analysis done by investigators of the National Institutes of Health/ National Heart, Lung, and Blood Institute Severe Asthma Research Program pediatric cohort, children with severe asthma had higher serum IgE and increased aeroallergen sensitization. ${ }^{10,38}$ As already described, IgE is a key factor in T2 high inflammation. Attachment of allergens to FceRI-bound $\mathrm{IgE}$ and cross-linking of $\mathrm{IgE}$ receptors initiate a signaling cascade that leads to release of histamine, leukotrienes, and other inflammatory factors by human mast cells. Dendritic cells uptake and process the allergen, subsequently presenting it to naïve $T$ cells and shifting them toward a $T_{H} 2$ pathway. Dendritic and B-cell antigen presentation may be facilitated through binding of allergen and specific $\operatorname{IgE}$ attached to the high-affinity receptor on the cell surface. This $\mathrm{T}_{\mathrm{H}} 2$ shift contributes to the perpetuation of allergen-specific $\operatorname{IgE}$ production. IgE also activates eosinophils and macrophages through the FceRI receptor to produce proinflammatory cytokines that are involved in tissue remodeling. Airway smooth muscles also express FceRI, and via IgE activation type I and III collagen production is increased, as seen in asthma remodeling. ${ }^{39}$

To date, omalizumab is the only available IgE-targeted therapy approved for poorly controlled moderate-severe persistent asthma. The presence of perennial sensitization and total serum IgE within range with specified body weight $(0.016 \mathrm{mg} / \mathrm{kg}$ of body weight per international unit of $\mathrm{IgE} /$ $\mathrm{mL}$ not to exceed $750 \mathrm{mg}$ per month) is the approved dosing for omalizumab. Total $\operatorname{IgE}$ is not a reliable indicator of response to omalizumab, although the presence of an 
increased quantity of IgE specific to relevant allergens may predict response. Clinical trials have demonstrated a rapid decrease in serum free $\operatorname{IgE}$ after initiation. The reduction of serum free $\mathrm{IgE}$ to a concentration of $\leq 20.8 \mathrm{IU} / \mathrm{mL}$ in response to omalizumab is likely required for a consistent therapeutic response. ${ }^{40-42}$ In a pediatric population, the reduction in free serum IgE levels after omalizumab treatment is associated with a decrease in seasonal exacerbations secondary to rhinovirus. ${ }^{43}$ Therefore, modification of allergy influences nonallergic asthma triggers. Unfortunately, commercially available assays are not able to distinguish between the omalizumab-IgE complex and free IgE. Once on therapy, the measurement of serum IgE reflects omalizumab-IgE complexes, and thus serum IgE during treatment is not an indicator of free $\mathrm{IgE}$ nor a predictor of therapeutic response to omalizumab. In conclusion, the concentration of total serum $\mathrm{IgE}$ and presence of specific IgE are useful biomarkers for identification of allergic asthma and potential candidates for omalizumab therapy.

\section{Expiratory lung-function measurements}

$\mathrm{FEV}_{1}$ is an essential component of pulmonary function testing used to diagnose and monitor asthma. Low $\mathrm{FEV}_{1}$ is a clinical sign suggestive of increased asthma severity. Casale et al illustrated that clinical signs of asthma severity were predictive of omalizumab response, and patients with $\mathrm{FEV}_{1}<65 \%$ predicated had a greater reduction in exacerbation rates following omalizumab therapy. ${ }^{26}$ In a multicenter retrospective analysis of patients with severe asthma treated with omalizumab, the authors evaluated the role of lung-function studies in responders to omalizumab. Patients were separated into responders and nonresponders to treatment based on physician assessment and the use of global evaluation of treatment effectiveness. Lungfunction parameters were measured at baseline and 6, 12, and 24 months. Patients in the responder group had 5.7\% improvement in $\mathrm{FEV}_{1}$ after 6 months of therapy. Forced expiratory flow $25 \%-75 \%$ also improved within the first 6 months. The authors also noted a greater improvement in residual volume in those patients with severe obstructive airway $\left(\mathrm{FEV}_{1}<50 \%\right.$ predicted), suggesting the possible impact of omalizumab on small airways. ${ }^{44}$ Currently in Europe, $\mathrm{FEV}_{1}<80 \%$ is required for the approval of omalizumab. ${ }^{44}$ In summary, $\mathrm{FEV}_{1}$ is a readily available clinical marker to predict severity of asthma and hence response to omalizumab.

\section{From bench side to bedside}

Asthma populations are heterogeneous, and the challenge remains to treat patients effectively and be prudent with health care resources. Several "real-life" studies published since 2008 have attempted to predict effectiveness of omalizumab based on clinical history and presentation. In a review of 24 real-life effectiveness studies of omalizumab in the treatment of severe allergic asthma, 4,117 unique cases from 32 countries were reviewed. The authors described the profile of patients more likely to have greater therapeutic benefit from omalizumab. Impaired lung function $(<40 \%-45 \%$ of predicted $\mathrm{FEV}_{1}$ ), increased daytime and nighttime symptoms, prior history of exacerbation, and significantly impaired quality of life were associated with greater therapeutic benefit from omalizumab. ${ }^{45} \mathrm{~A}$ small retrospective study of 41 patients with severe allergic asthma treated with omalizumab used FeNO, peripheral eosinophils, periostin, total serum IgE, and $\mathrm{FEV}_{1}$ in combination with the clinical symptoms of quality of life scores and prior history of exacerbation. At 16 weeks, of the 41 patients treated, the authors defined 28 individuals as responders to omalizumab by assessing improvement in night and day symptoms, reduced usage of rescue medication, reduction in exacerbation, and improvement in morning peak-flow rate by $>15 \% .{ }^{46}$ Consistent with other studies, responders benefited within 16 weeks from initiation of therapy. These authors also reported that $\mathrm{FEV}_{1} \leq 69 \%$ of predicated at baseline was a good predictor for response to omalizumab. ${ }^{46}$ Responders to omalizumab experienced an improvement in AQLQ and decreased exacerbations within 16-32 weeks. Most clinicians recommend a trial of at least 6 months to assess response to treatment.

Currently there is no consensus on duration of omalizumab therapy in those who benefit. In real-life studies at 4 and 9 years of use of omalizumab, patients showed persistent, significant improvement in AQLQ, decreased exacerbations, and slight improvement in $\mathrm{FEV}_{1}$ compared to baseline. ${ }^{47}$

\section{Conclusion}

Many asthma studies provide evidence of omalizumab efficacy with reduced exacerbations and improved symptoms and quality of life in adults and children. However, some patients do not benefit. Allergic asthma is a phenotype that has been consistently used as a criterion for initiation of omalizumab. Nonallergic asthma has been treated successfully with omalizumab, but the mechanism of action in this situation is not understood. ${ }^{48}$ Better clarification of asthma endotypes will likely improve the accuracy of predicting response. Currently available biomarkers are limited in number and precision, but are of value. The combination of a history of frequent exacerbations, decreased $\mathrm{FEV}_{1}$, presence of total serum IgE within dosing range (30-700 IU/ $\mathrm{mL}$ in adolescents and adults and $30-1,300 \mathrm{IU} / \mathrm{mL}$ in children 


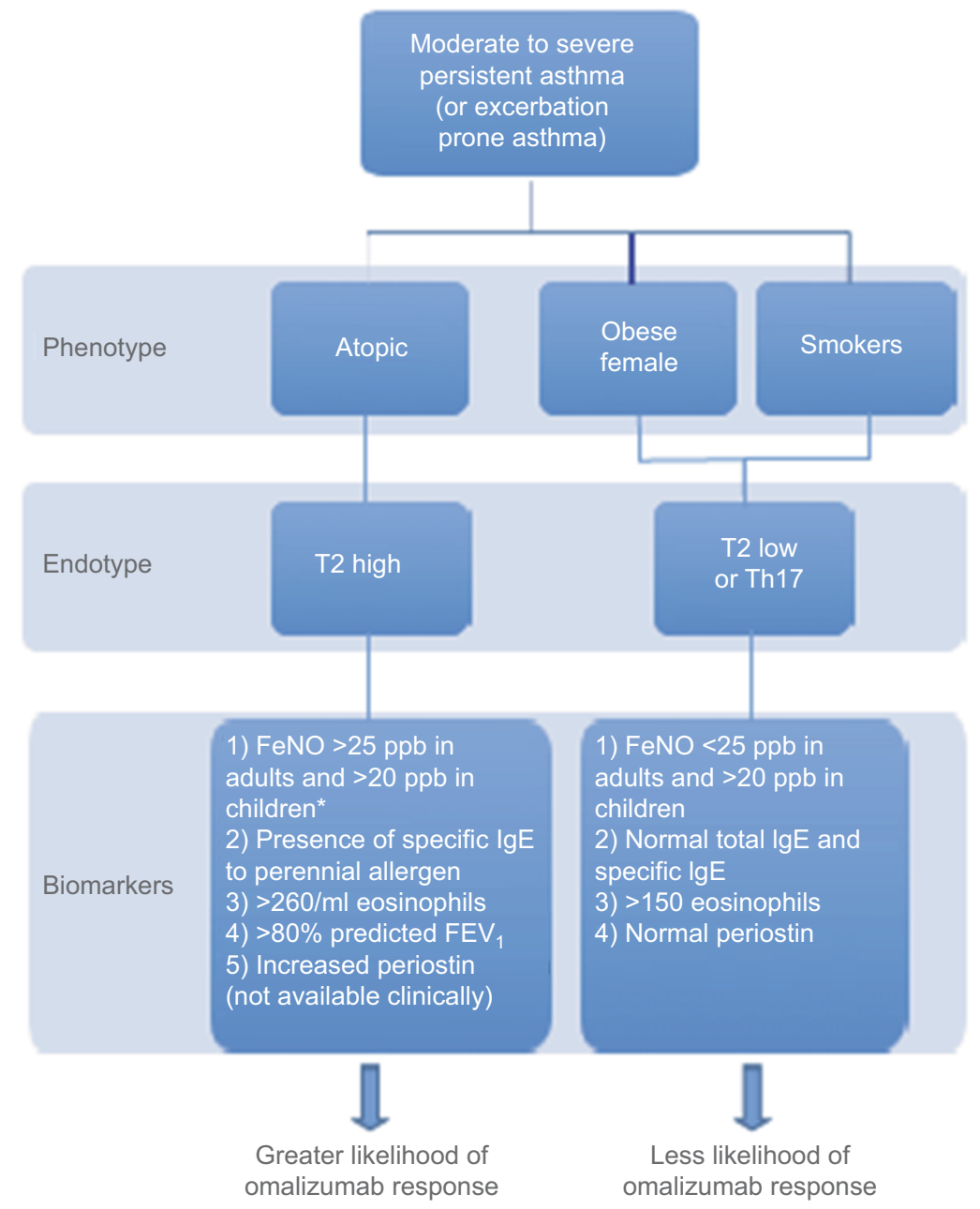

Figure $3 \mathrm{~A}$ way to categorize patients with moderate-severe asthma in clinical settings using available biomarkers.

Note: *FeNO $>50 \mathrm{ppb}$ ( $>35 \mathrm{ppb}$ in children) or rising FeNO ( $>40 \%$ change from previously stable levels) is associated with possible uncontrolled inflammation, poor inhaler use, or steroid resistance.

Abbreviation: FeNO, fractional exhaled nitric oxide.

aged 6-12 years), allergen-specific IgE, increased FeNO, and increased blood eosinophils are associated with greater likelihood of response to omalizumab (Figure 3). Persistent increase of eosinophils during therapy or an increase in FeNO following discontinuation may predict the need for continued therapy. Endotype recognition and associated markers will advance personalized asthma care to move beyond the one-size-fits-all or trial-and-error approach.

\section{Disclosure}

DKL has received research support (paid to University) from Genentech/Roche and AstraZeneca, consultant fees from AstraZeneca, speakers' bureau fees from AstraZeneca, Genentech/Roche, Meda, Novartis, and Teva, and fees for legal opinions on drug allergy, metal allergy, radiocontrast reaction, and asthma death. The authors report no other conflicts of interest in this work.

\section{References}

1. Fajt ML, Wenzel SE. Development of new therapies for severe asthma. Allergy Asthma Immunol Res. 2017;91:3-14.

2. Barnes PJ, Jonsson B, Klim JB. The costs of asthma. Eur Respir J. 1996;94:636-42.

3. Chung KF. Managing severe asthma in adults: lessons from the ERS/ ATS guidelines. Curr Opin Pulm Med. 2015;211:8-15.

4. Moore WC, Meyers DA, Wenzel SE, et al. Identification of asthma phenotypes using cluster analysis in the Severe Asthma Research Program. Am J Respir Crit Care Med. 2010;1814:315-323.

5. Haldar P, Pavord ID, Shaw DE, et al. Cluster analysis and clinical asthma phenotypes. Am J Respir Crit Care Med. 2008;1783:218-224.

6. Bourdin A, Molinari N, Vachier I, et al. Prognostic value of cluster analysis of severe asthma phenotypes. J Allergy Clin Immunol. 2014;1345:1043-1050.

7. Xolair 2017 [updated 2017]. Available from: http://www.xolair.com/ allergic-asthma/hcp.

8. Halwani R, Sultana A, Vazquez-Tello A, Jamhawi A, Al-Masri AA, AlMuhsen S. Th-17 regulatory cytokines IL-21, IL-23, and IL-6 enhance neutrophil production of IL-17 cytokines during asthma. JAsthma. Epub 2017 Mar 2.

9. Fahy JV. Type 2 inflammation in asthma: present in most, absent in many. Nat Rev Immunol. 2015;151:57-65. 
10. Chipps BE, Lanier B, Milgrom H, et al. Omalizumab in children with uncontrolled allergic asthma: review of clinical trial and real-world experience. J Allergy Clin Immunol. 2017;1395:1431-1444.

11. Samitas K, Delimpoura V, Zervas E, Gaga M. Anti-IgE treatment, airway inflammation and remodelling in severe allergic asthma: current knowledge and future perspectives. Eur Respir Rev. 2015;24138:594-601.

12. Holowka D, Sil D, Torigoe C, Baird B. Insights into immunoglobulin E receptor signaling from structurally defined ligands. Immunol Rev. 2007;217:269-279.

13. Galli SJ, Tsai M. IgE and mast cells in allergic disease. Nat Med. 2012;185:693-704.

14. MacGlashan DW Jr, Bochner BS, Adelman DC, et al. Down-regulation of FceRI expression on human basophils during in vivo treatment of atopic patients with anti-IgE antibody. J Immunol. 1997;1583:1438-1445.

15. Mitchell PD, El-Gammal AI, O'Byrne PM. Anti-IgE and biologic approaches for the treatment of asthma. Handb Exp Pharmacol. 2017;237:131-152.

16. Ledford D, Busse W, Trzaskoma B, et al. A randomized multicenter study evaluating Xolair persistence of response after long-term therapy. J Allergy Clin Immunol. 2017;140:162.e2-169.e2.

17. Chan MA, Gigliotti NM, Dotson AL, Rosenwasser LJ. Omalizumab may decrease IgE synthesis by targeting membrane IgE+ human B cells. Clin Transl Allergy. 2013;3:29.

18. Bousquet J, Cabrera P, Berkman N, et al. The effect of treatment with omalizumab, an anti-IgE antibody, on asthma exacerbations and emergency medical visits in patients with severe persistent asthma. Allergy. 2005;603:302-308.

19. Humbert M, Busse W, Hanania NA, et al. Omalizumab in asthma: an update on recent developments. J Allergy Clin Immunol Pract. 2014;25:525.e1-536.e1.

20. Hanania NA, Wenzel S, Rosén K, et al. Exploring the effects of omalizumab in allergic asthma: an analysis of biomarkers in the EXTRA study. Am J Respir Crit Care Med. 2013;1878:804-811.

21. Berry A, Busse WW. Biomarkers in asthmatic patients: has their time come to direct treatment? J Allergy Clin Immunol. 2016;1375: $1317-1324$

22. Pavord ID, Korn S, Howarth P, et al. Mepolizumab for severe eosinophilic asthma (DREAM): a multicentre, double-blind, placebocontrolled trial. Lancet. 2012;380:651-659.

23. Pizzichini E, Pizzichini MM, Efthimiadis A, Dolovich J, Hargreave FE. Measuring airway inflammation in asthma: eosinophils and eosinophilic cationic protein in induced sputum compared with peripheral blood. J Allergy Clin Immunol. 1997;994:539-544.

24. Price DB, Rigazio A, Campbell JD, et al. Blood eosinophil count and prospective annual asthma disease burden: a UK cohort study. Lancet Respir Med. 2015;311:849-858.

25. Mansur AH, Srivastava S, Mitchell V, Sullivan J, Kasujee I. Longterm clinical outcomes of omalizumab therapy in severe allergic asthma: study of efficacy and safety. Respir Med. 2017;124:36-43.

26. Casale TB, Chipps BE, Rosén K, et al. Response to omalizumab using patient enrichment criteria from trials of novel biologics in asthma. Allergy. Epub 2017 Aug 31.

27. Busse W, Spector S, Rosén K, Wang Y, Alpan O. High eosinophil count: a potential biomarker for assessing successful omalizumab treatment effects. J Allergy Clin Immunol. 2013;1322:485.e11-486.e11.

28. Rank MA, Ochkur SI, Lewis JC, et al. Nasal and pharyngeal eosinophil peroxidase levels in adults with poorly controlled asthma correlate with sputum eosinophilia. Allergy. 2016;714:567-570.

29. Wright K. Bioactive paper will revolutionize point-of-care diagnostics 2013. Available from: http://dailynews.mcmaster.ca/article/bioactive-paperwill-revolutionize-point-of-care-diagnostics. Accessed October 28, 2017.

30. Dweik RA, Boggs PB, Erzurum SC, et al. An official ATS clinical practice guideline: interpretation of exhaled nitric oxide levels FENO for clinical applications. Am J Respir Crit Care Med. 2011;1845:602-615.
31. Mehta V, Stokes JR, Berro A, Romero FA, Casale TB. Time-dependent effects of inhaled corticosteroids on lung function, bronchial hyperresponsiveness, and airway inflammation in asthma. Ann Allergy Asthma Immunol. 2009;1031:31-37.

32. Petsky HL, Kew KM, Chang AB. Exhaled nitric oxide levels to guide treatment for children with asthma. Cochrane Database Syst Rev. 2016;11:CD011439.

33. Petsky HL, Kew KM, Turner C, Chang AB. Exhaled nitric oxide levels to guide treatment for adults with asthma. Cochrane Database Syst Rev. 2016;9:CD011440.

34. Pijnenburg MW, Bakker EM, Lever S, Hop WC, De Jongste JC. High fractional concentration of nitric oxide in exhaled air despite steroid treatment in asthmatic children. Clin Exp Allergy. 2005;357: 920-925.

35. Haldar P, Brightling CE, Hargadon B, et al. Mepolizumab and exacerbations of refractory eosinophilic asthma. $N$ Engl J Med. 2009;360:973-984.

36. Corren J, Wood RA, Patel D, et al. Effects of omalizumab on changes in pulmonary function induced by controlled cat room challenge. JAllergy Clin Immunol. 2011;1272:398-405.

37. Tajiri T, Matsumoto H, Gon Y, et al. Utility of serum periostin and free $\mathrm{IgE}$ levels in evaluating responsiveness to omalizumab in patients with severe asthma. Allergy. 2016;7110:1472-1479.

38. Fitzpatrick AM, Teague WG, Meyers DA, et al. Heterogeneity of severe asthma in childhood: confirmation by cluster analysis of children in the National Institutes of Health/National Heart, Lung, and Blood Institute Severe Asthma Research Program. J Allergy Clin Immunol. 2011;1272:382-389.e1-e13.

39. Pelaia G, Canonica GW, Matucci A, Paolini R, Triggiani M, Paggiaro P. Targeted therapy in severe asthma today: focus on immunoglobulin E. Drug Des Devel Ther. 2017;11:1979-87.

40. Berger W, Gupta N, McAlary M, Fowler-Taylor A. Evaluation of longterm safety of the anti-IgE antibody, omalizumab, in children with allergic asthma. Ann Allergy Asthma Immunol. 2003;912:182-188.

41. Milgrom H, Berger W, Nayak A, et al. Treatment of childhood asthma with anti-immunoglobulin E antibody (omalizumab). Pediatrics. 2001;108:E36.

42. Korn S, Haasler I, Fliedner F, et al. Monitoring free serum IgE in severe asthma patients treated with omalizumab. Respir Med. 2012;106:1494-1500.

43. Teach SJ, Gill MA, Togias A, et al. Preseasonal treatment with either omalizumab or an inhaled corticosteroid boost to prevent fall asthma exacerbations. J Allergy Clin Immunol. 2015;136:1476-1485.

44. Paganin F, Mangiapan G, Proust A, et al. Lung function parameters in omalizumab responder patients: an interesting tool? Allergy. Epub 2017 May 18.

45. Abraham I, Alhossan A, Lee CS, Kutbi H, MacDonald K. 'Real-life' effectiveness studies of omalizumab in adult patients with severe allergic asthma: systematic review. Allergy. 2016;71:593-610.

46. Kallieri M, Papaioannou AI, Papathanasiou E, Ntontsi P, Papiris S, Loukides S. Predictors of response to therapy with omalizumab in patients with severe allergic asthma: a real life study. Postgrad Med.2017; 129:598-604.

47. Menzella F, Galeone C, Formisano D, et al. Real-life efficacy of omalizumab after 9 years of follow-up. Allergy Asthma Immunol Res. 2017;94:368-372.

48. Garcia G, Magnan A, Chiron R, et al. A proof-of-concept, randomized, controlled trial of omalizumab in patients with severe, difficult-tocontrol, nonatopic asthma. Chest. 2013;144:411-419.

49. Lambrecht BN, Hammad H. The immunology of asthma. Nat Immunol. 2015;161:45-56.

50. Kupryś-Lipińska I, Molińska K, Kuna P. The effect of omalizumab on eosinophilic inflammation of the respiratory tract in patients with allergic asthma. Pneumonol Alergol Pol. 2016;844:232-243. 
Journal of Asthma and Allergy

The Journal of Asthma and Allergy is an international, peer-reviewed open access journal publishing original research, reports, editorials and commentaries on the following topics: Asthma; Pulmonary physiology; Asthma related clinical health; Clinical immunology and the immunological basis of disease; Pharmacological interventions and new therapies. This journal is included in PubMed. The manuscript management system is completely online and includes a very quick and fair peer-review system, which is all easy to use. Visit http://www. dovepress.com/testimonials.php to read real quotes from published authors.

Submit your manuscript here: https://www.dovepress.com/journal-of-asthma-and-allergy-journal 